\title{
Radiofrequency ablation of pancreas and optimal cooling of peripancreatic tissue in an ex-vivo porcine model
}

\author{
Michal Crha ${ }^{1}$, Jan Hlavsa², Vladimír Procházka², Tomáš Andrašina ${ }^{3}$, \\ Iva Svobodová ${ }^{4}$, Lucie Urbanová ${ }^{1}$, Tomáš Pavlík ${ }^{5}$, Petr Raušer ${ }^{1}$, Jana Lorenzová1, \\ Zdeněk Kala ${ }^{2}$, Alois Nečas ${ }^{1}$ \\ ${ }^{1}$ Department of Surgery and Orthopaedics, Small Animal Clinic, Faculty of Veterinary Medicine, \\ University of Veterinary and Pharmaceutical Sciences Brno, Czech Republic \\ ${ }^{2}$ Department of Surgery, ${ }^{3}$ Department of Radiology, University Hospital Brno Bohunice and Faculty \\ of Medicine, Masaryk University Brno, Czech Republic \\ ${ }^{4}$ Department of Pathology, Saint Anne's University Hospital Brno and Faculty of Medicine, Masaryk University \\ Brno, Czech Republic \\ ${ }^{5}$ Institute of Biostatistics and Analysis, Faculty of Medicine, Masaryk University Brno, Czech Republic
}

Received November 15, 2010

Accepted November 15, 2011

\begin{abstract}
Radiofrequency ablation is a possible palliative treatment for patients suffering from pancreatic neoplasia. However, radiofrequency-induced damage to the peripancreatic tissues during pancreatic ablation might cause fatal complications. The aim of this experimental ex vivo study on pigs was to verify ablation protocols and evaluate whether or not the cooling of peripancereatic tissues during pancreatic ablation has any benefit for their protection against thermal injury. Radiofrequency ablation was performed on 52 pancreatic specimens obtained from pigs. During each pancreatic ablation, continuous measurements of the temperature in the portal vein and duodenal lumen were performed. Peripancreatic tissues were either not cooled or were cooled by being submerged in $14^{\circ} \mathrm{C}$ water, or by a perfusion of the portal vein and duodenum with 14 ${ }^{\circ} \mathrm{C}$ saline. The effects of variation in target temperature of the ablated area $\left(90^{\circ} \mathrm{C}\right.$ and $\left.100{ }^{\circ} \mathrm{C}\right)$, duration of ablation (5 and $10 \mathrm{~min}$ ) and the effect of peripancreatic tissues cooling were studied. We proved that optimal radiofrequency ablation of the porcine pancreas can be reached with the temperature of $90^{\circ} \mathrm{C}$ for $5 \mathrm{~min}$ in the ablated area. The perfusion of the duodenal and portal vein by $14{ }^{\circ} \mathrm{C}$ saline was found to be the most effective cooling method for minimizing damage to the walls. Continuous measurement of temperatures in peripancreatic tissues will provide useful feedback to assist in their protection against thermal injury. This therapy could be used in the treatment of pancreatic tumours.
\end{abstract}

Tumour, radiotherapy, thermal injury, duodenum, portal vein, pig

Radiofrequency ablation (RFA) is a thermo-physical method using high frequency alternating current for destruction (thermocoagulation) of the tissue. Since the 1990s RFA has also been used in human oncology, as one of the methods of tumour destruction. Several studies have been performed using ex vivo and/or in vivo animal models to verify the effectiveness of RFA on various tissue types including the pancreas (Johnson and Cadeddu 2003; Date et al. 2005a,b; Lee et al. 2005). It has been already applied to ablation for primary and secondary tumours of the liver, lung, breast, kidney, adrenal gland, prostate, brain, bones and biliary tract (Singletary 2003; Wood et al. 2003; Gananadha et al. 2004; Penka et al. 2004; Boss et al. 2005; Jansen et al. 2005; Martel et al. 2005; Shariat et al. 2005; Penka et al. 2008). It has been used successfully for the treatment of primary hyperparathyroidism in dogs (Pollard et al. 2001) and hyperthyroidism in cats (Mallery et al. 2003). There are also several studies describing radiofrequency ablation of pancreatic tumours (Hlavsa et al. 2008; Limmer et al. 2009; Casadei et al. 2010). Radiofrequency ablation might be one of the treatment options in patients with unresectable

Address for correspondence:

MVDr. Michal Crha, Ph.D.

Department of Surgery and Orthopaedics

Small Animal Clinic

Faculty of Veterinary Medicine

University of Veterinary and Pharmaceutical Sciences Brno

Palackeho 1-3, 61242 Brno, Czech Republic 
pancreatic tumours in both veterinary and human medicine. However, this new approach to the treatment of pancreatic malignancies is limited by the high rate of perioperative complications, including biliary or duodenal fistula, bleeding from peripancreatic veins and arteries and acute pancreatitis which can be fatal (Date et al. 2005b; Casadei et al. 2010).

Before further clinical use of this method in veterinary and human surgery, it is therefore necessary to create a safe RFA technique for the pancreas, which would provide proper and predictable pancreatic parenchyma destruction with minimal risk of complications. In this experimental comparative study we have tried to determine the ablation protocol (time of ablation and average temperature in the ablated area) and the type of cooling of peripancreatic tissues (portal vein, duodenum) in order to establish a feasible and safe technique of radiofrequency ablation of pancreatic tissue.

\section{Materials and Methods}

The radiofrequency ablation was performed on 52 porcine pancreases that were obtained from healthy animals slaughtered at a commercial abattoir. We used a similar procedure describing previously by Date et al. (2005a) for the preparation of an ex vivo study of pancreatic radiofrequency ablation, which was modified by the use of cooling and perioperative measurement of the temperature in the target tissues i.e. the portal vein and duodenum. All 52 pancreas specimens were divided into three groups: $\mathrm{A}(\mathrm{n}=18)$, where radiofrequency ablation was performed without any cooling, $\mathrm{B}(\mathrm{n}=17)$ where pancreas and peripancreatic tissue were submerged in $14{ }^{\circ} \mathrm{C}$ water during ablation, $\mathrm{C}(\mathrm{n}=17)$ where the duodenum and portal vein were cooled by a perfusion of $14{ }^{\circ} \mathrm{C}$ saline (Plate VIII, Fig. 1). An RFA generator (RITA 1500X, Angiodynamics, Manchester GA, USA) with a $2 \mathrm{~cm}$ umbrella RFA electrode (StarBurst XL Electrode, length $15 \mathrm{~cm}$; O.D $14 \mathrm{Ga} / 6.4 \mathrm{~F}$ ) was used for all the ablations.

Each group was divided into three subgroups (e.g. $\left.A^{90 / 5}, A^{90 / 10}, A^{100 / 5}\right)$. In subgroups $A^{90 / 5}(n=6), B^{90 / 5}(n=6)$ and $\mathrm{C}^{90 / 5}(\mathrm{n}=6)$, radiofrequency ablation of the pancreatic tissue was performed with an average temperature of $90^{\circ} \mathrm{C}$ applied for $5 \mathrm{~min}$. In subgroups $\mathrm{A}^{90 / 10}(\mathrm{n}=6), \mathrm{B}^{90 / 10}(\mathrm{n}=5)$ and $\mathrm{C}^{90 / 10}(\mathrm{n}=6)$, an average temperature of $90^{\circ} \mathrm{C}$ for 10 min was used. In subgroups $\mathrm{A}^{100 / 5}(\mathrm{n}=6), \mathrm{B}^{100 / 5}(\mathrm{n}=6)$ and $\mathrm{C}^{100 / 5}(\mathrm{n}=5)$, an average temperature of $100{ }^{\circ} \mathrm{C}$ for 5 min was used.

During each ablation, the temperatures inside the duodenum and portal vein were continuously measured using special electrodes connected to the thermal data acquisition system OMEGA (OMB-DAQ-56, 20 channel 22 bit das system, OMEGA engineering Inc., Stamford, CT, US). Each specimen was preserved in formol and microscopically examined.

The damage to the duodenal wall and the portal vein wall, as well as the diameter of pancreatic necrosis was microscopically evaluated using a haematoxylin eosin and acid fuchsin orange stain technique (Plate VIII, Fig. 2). Three degrees of damage were separately determined for the duodenal and portal vein walls (Table 1).

The diameter of pancreatic necrosis as well as damage to the portal vein wall and duodenal wall were compared with the ablation protocols, the types of cooling and the maximal temperatures inside the duodenum and portal vein.

A basic cohort description was performed using frequency tables and descriptive statistics (average, median, minimum and maximum). For testing the differences between the continuous values (pancreas necrosis diameter, temperature) of groups A, B, C, the standard nonparametric Kruskal-Walis test was applied. For evaluation of the categorical parameters (degree of portal vein wall and duodenal wall damage), Pearson's Chi-square test was used. As the significance limit of 0.05 was used, $p$ values below 0.05 were viewed as significant.

Table 1. Radiofrequency ablation of porcine pancreases: degrees of duodenal and portal vein walls damage.

\begin{tabular}{|c|c|}
\hline Degree of duodenal wall damage & Microscopic description of thermal damage \\
\hline 1 - Mild damage & Changes in serosa and the outer half of the muscular layer \\
\hline 2 - Moderate damage & $\begin{array}{l}\text { Changes in the whole width of the muscular layer, } \\
\text { no change in the submucosa and mucosa }\end{array}$ \\
\hline 3 - Severe damage & Changes in submucosa and muscularis mucosae \\
\hline \multicolumn{2}{|l|}{ Degree of portal vein wall damage } \\
\hline 1 - Mild damage & Changes in $1 / 3$ of the wall width \\
\hline 2 - Moderate damage & Changes in $2 / 3$ of the wall width \\
\hline 3 - Severe damage & Changes in whole the wall width \\
\hline
\end{tabular}




\section{Results and Discussion}

We have found a significant $(p<0.001)$ relationship between the size of necrosis and type of cooling (Fig. 3$)$. In contrast, no significant $(p=0.746)$ correlation between the size of necrosis and ablation protocol was found (Fig. 4). It appears that a final temperature of 90 and/or $100{ }^{\circ} \mathrm{C}$ in the ablated area were similarly effective for

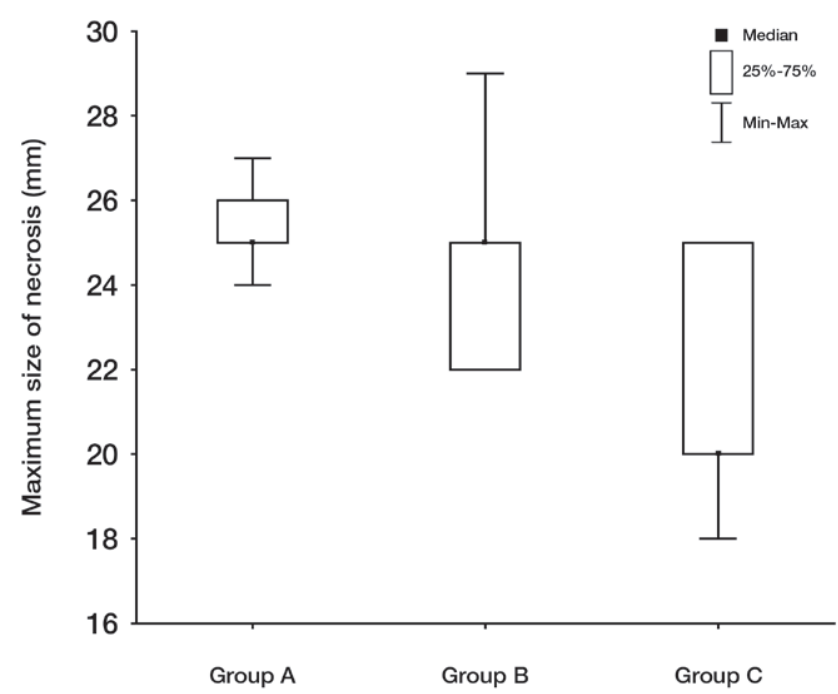

Fig. 3. Radiofrequency ablation of porcine pancreas with perfusion of the duodenum and portal vein with $14{ }^{\circ} \mathrm{C}$ cold saline.

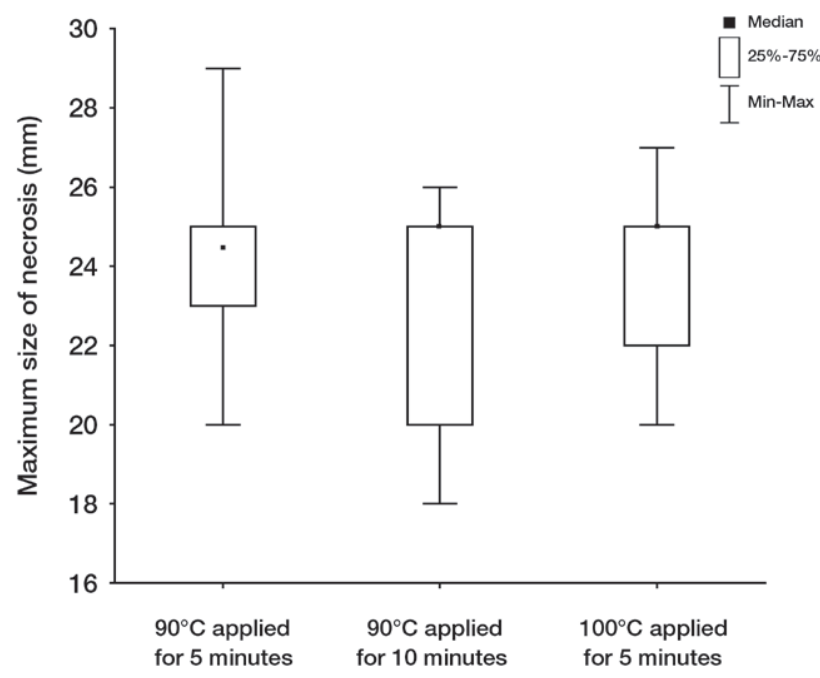

Fig. 4. Portal vein wall (AFOG - acid fuchsin orange G) stain - severe thermal changes visible in the whole width of the portal vein wall. 


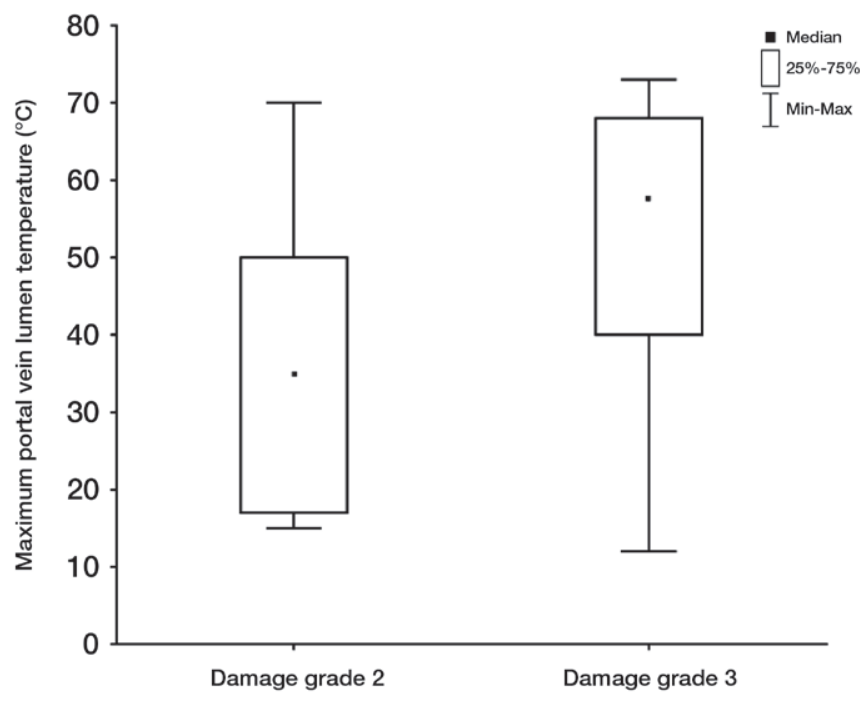

Fig. 5. Radiofrequency ablation of porcine pancreas: Relationship between maximal portal vein lumen temperature and degree of damage of its wall $(p=0.03)$.

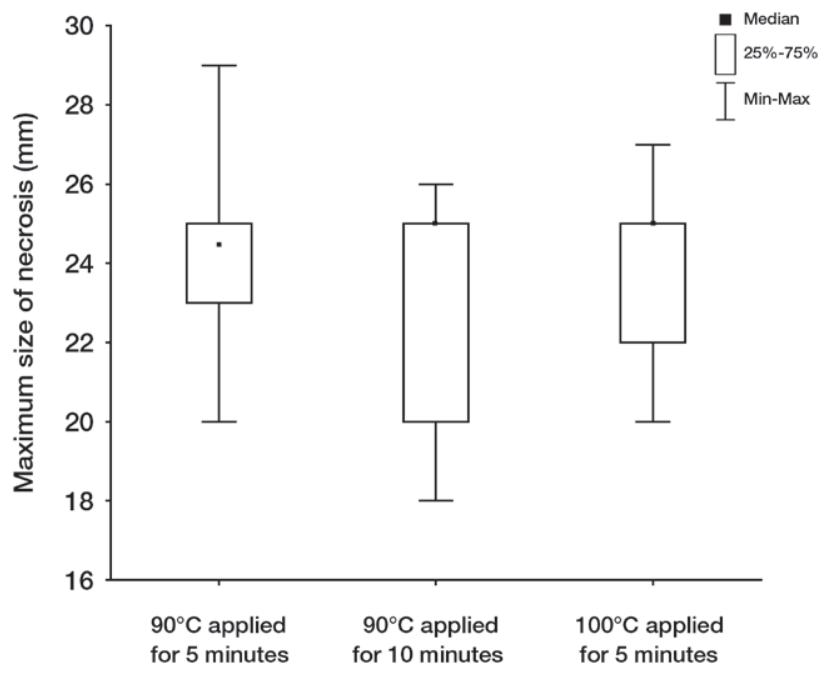

Fig. 6. Relationship between the maximal duodenal lumen temperature and degree of damage to the duodenal wall during radiofrequency ablation of porcine pancreas.

sufficient destruction of pancreatic tissue, which corresponds to the findings described by Date et al. (2005a). In other words, the size of necrosis in our experimental model of porcine pancreas can be influenced by the type of cooling and not by the ablation protocol used. 
We have proved a significant relationship between the maximal temperature reached in the portal vein, and the degree of damage of its wall (Fig. 5). Higher lumen temperatures caused major portal vein wall destruction. Correlation between the maximal temperature in the duodenal lumen and the degree of duodenal wall damage was not significant $(p=0.361)$ because of few measurements. Nevertheless, there was the trend of increasing duodenal wall destruction with maximal rises in temperature (Fig. 6). Regarding the results of our ex vivo model, we determined that by utilizing continuous measurement of the temperature in peripancreatic tissues during pancreatic RFA, the severity of damage could be reduced.

Table 2. Relationship of portal vein wall damage and type of cooling after radiofrequency ablation of porcine pancreases.

\begin{tabular}{|c|c|c|c|}
\hline \multirow{2}{*}{ Type of cooling } & \multicolumn{2}{|c|}{ Degree of damage $-\mathrm{n}(\%)$} & \multirow[t]{2}{*}{ Total } \\
\hline & 2 & 3 & \\
\hline Group A & $3(17.7 \%)$ & $14(82.4 \%)$ & $17(33.3 \%)$ \\
\hline Group B & $5(29.4 \%)$ & $12(70.6 \%)$ & $17(33.3 \%)$ \\
\hline Group C & $11(64.7 \%)$ & $6(35.3 \%)$ & $17(33.3 \%)$ \\
\hline Total & $19(37.3 \%)$ & $32(62.7 \%)$ & $51(100 \%)$ \\
\hline
\end{tabular}

Pearson's Chí-square test $p$-value 0.013

Table 3. Relationship of duodenal wall damage and type of cooling after radiofrequency ablation of porcine pancreases.

\begin{tabular}{lrrr}
\hline Type of cooling & \multicolumn{2}{c}{ Degree of damage $-\mathrm{n}(\%)$} & Total \\
\hline Group A & 1 or 2 & 3 & $18(34.6 \%)$ \\
Group B & $6(33 . \%)$ & $12(66.7 \%)$ & $17(32.7 \%)$ \\
Group C & $11(64.7 \%)$ & $6(35.3 \%)$ & $17(32.7 \%)$ \\
Total & $10(58 . \%)$ & $7(41.2 . \%)$ & $52(100 \%)$ \\
\hline
\end{tabular}

Pearson's Chí-square test $p$-value 0.140

Table 4. Relationship of portal vein wall damage and ablation protocol of porcine pancreas.

\begin{tabular}{lrrr}
\hline Ablation protocol & \multicolumn{2}{c}{ Degree of damage } & Total \\
\hline $90^{\circ} \mathrm{C} / 5 \mathrm{~min}$ & 2 & 3 & $17(33.3 \%)$ \\
$100^{\circ} \mathrm{C} / 5 \mathrm{~min}$ & $9(52.9 \%)$ & $8(47.1 \%)$ & $17(33.3 \%)$ \\
$90^{\circ} \mathrm{C} / 10 \mathrm{~min}$ & $6(35.3 \%)$ & $11(64.7 \%)$ & $17(33.3 \%)$ \\
Total & $4(23.5 \%)$ & $13(76.5 \%)$ & $51(100 \%)$ \\
\hline
\end{tabular}

Pearson's Chí-square test $p$-value 0.203

Table 5. Relationship of duodenal wall damage and ablation protocol of porcine pancreas.

\begin{tabular}{lrrr}
\hline Ablation protocol & \multicolumn{1}{c}{ Degree of damage } & Total \\
\hline $90^{\circ} \mathrm{C} / 5 \mathrm{~min}$ & $13(72.2 \%)$ & 3 & $18(34.6 \%)$ \\
$100^{\circ} \mathrm{C} / 5 \mathrm{~min}$ & $7(41.2 \%)$ & $10(58.8 \%)$ & $17(32.7 \%)$ \\
$90^{\circ} \mathrm{C} / 10 \mathrm{~min}$ & $7(41.2 \%)$ & $10(58.8 \%)$ & $17(32.7 \%)$ \\
Total & $27(51.9 \%)$ & $25(48.1 \%)$ & $52(100 \%)$ \\
\hline
\end{tabular}

Pearson's Chí-square test $p$-value 0.103 
There is also a significant relationship between portal vein wall damage and the type of cooling (Table 2). Correlation between duodenal wall damage and the type of cooling was not significant (Table 3). Damage of the portal vein wall and the duodenal wall was not shown to be significant regarding the dependence of the ablation protocol (Tables 4 and 5).

Despite this, Tables 4 and 5 show an increasing trend of duodenal and portal vein wall damage when approaching ablation protocols of $90{ }^{\circ} \mathrm{C} / 5 \mathrm{~min}, 100{ }^{\circ} \mathrm{C} / 5 \mathrm{~min}$, and $90{ }^{\circ} \mathrm{C} / 10 \mathrm{~min}$.

In conclusion, although some results were not significant, we have proved that optimal radiofrequency ablation of the porcine pancreas can be reached with the average temperature of $90^{\circ} \mathrm{C}$ in the ablated area for $5 \mathrm{~min}$. Continuous measurement of temperatures in peripancreatic tissues will aid their protection against thermal injury. The perfusion of the duodenal and portal vein lumina by $14{ }^{\circ} \mathrm{C}$ saline was found to be the most effective cooling method for minimizing damage to the walls. This combination of ablation protocol and type of cooling offers appropriate pancreatic parenchyma damage with a low risk of duodenal or portal vein injury.

\section{Acknowledgements}

This work was supported by the grant agency Ministry of Health Czech Republic (IGA MZ ČR) (Project No. NS10239-3/2009 and NS10419-3/2009).

\section{References}

Boss A, Clasen S, Kuczyk M, Anastasiadis A, Schmidt D, Graf H, Schick F, Claussen CD, Pereira PL 2005: Magnetic resonance - guided percutaneous radiofrequency ablation of renal cell carcinoma: a pilot clinical study. Invest Radiol 40: 583-590

Casadei R, Ricci C, Pezzilli R, Serra C, Calculli L, Morselli-Labate AM, Santini D, Minni F 2010: A prospective study on radiofrequency ablation locally advanced pancreatic cancer. Hepatobiliary Pancreat Dis Int 9: 306-311

Date RS, McMahon RF, Siriwardena AK 2005a: Radiofrequency ablation of the pancreas. I: Definition of optimal thermal kinetic parameters and the effect of simulated portal venous circulation in a ex-vivo porcine model. J Pancreas (Online) 6: 581-587

Date RS, Siriwardena AK 2005b: Radiofrequency ablation of the pancreas. II: Intra-operative ablation of nonresectable pancreatic cancer. A description of technique and initial outcome. J Pancreas (Online) 6: 588-592

Gananadha S, Wulf S, Morris DL 2004: Safety and efficacy of radiofrequency ablation of brain: a potentially minimally invasive treatment for brain tumours. Minim Invasive Neurosurg 47: 325-328

Hlavsa J, Kala Z, Válek V, Mikulica M, Man M, Procházka V, Kiss I 2008: Radiofrequency ablation (RFA) of pancreatic tumors. Rozhl Chir 87: 462-466

Jansen MC, van Hillegersberg R, Chamuleau RA, van Delden OM, Gouma DJ, van Gulik TM 2005: Outcome of regional and local ablative therapies for hepatocellular carcinoma: a collective review. Surg Oncol 31: $331-347$

Johnson DB, Cadeddu JA 2003: Radiofrequency interstitial tumor ablation: dry electrode. J Endourol 17: $557-562$

Lee JM, Choi SH, Park HS, Lee MW, Han CJ, Choi JI, Choi JY, Hong SH, Han JK, Choi BI 2005: Radiofrequency thermal ablation in canine femur: evaluation of coagulation necrosis reproducibility and MRI-histopathologic correlation. Am J Roentgenol 185: 661-667

Limmer S, Huppert PE, Juette V, Lenhart A, Welte M, Wietholtz H 2009: Radiofrequency ablation of solitary pancreatic insulinoma in a patient with episodes of severe hypoglycemia. Eur J Gastroentero Hepatol 21: 1097-1101

Mallery KF, Pollard RE, Nelson RW, Hornof WJ, Feldman EC 2003: Percutaneous ultrasound-guided radiofrequency heat ablation for treatment of hyperthyroidism in cats. J Am Vet Med Assoc 223: 1602-1607

Martel J, Bueno A, Ortiz E 2005: Percutaneous radiofrequency treatment of osteoid osteoma using cool-tip electrodes. Eur J Radiol 56: 403-408

Penka I, Kaplan Z, Šefr R, Sirotek L, Eber Z, Ondrák M 2008: Use of radiofrequency ablation in the treatment of malignant liver lesions. Hepatogastrology 55: 562-567

Penka I, Šefr R, Kaplan Z, Ondrák M, Bartoňková H, Buřilová, H. Radiofrequency ablation of primary and metastatic hepatic tumors. 12th Congress of the European Society of Surgical Oncology (EJSO), Budapest, 31.March - 3.April, 2004

Pollard RE, Long CD, Nelson RW, Hornof WJ, Feldman EC 2001: Percutaneous ultrasonographically guided radiofrequency heat ablation for treatment of primary hyperparathyroidism in dogs. J Am Vet Med Assoc 218: $1106-1011$ 
Shariat SF, Raptidis G, Masatoschi M, Bergamaschi F, Slawin KM 2005: Pilot study of radiofrequency interstitial tumor ablation (RITA) for the treatment of radio-recurrent prostate cancer. Prostate 64: 260-267

Singletary ES 2003: Feasibility of radiofrequency ablation for primary breast cancer. Breast Cancer 10: 4-9

Wood BJ, Abraham J, Hvizda JL, Alexander HR, Fojo T 2003: Radiofrequency ablation of adrenal tumors and adrenocortical carcinoma metastases. Cancer 97: 554-560 
Crha M. et al.: Radiofrequency ... pp. 407-413

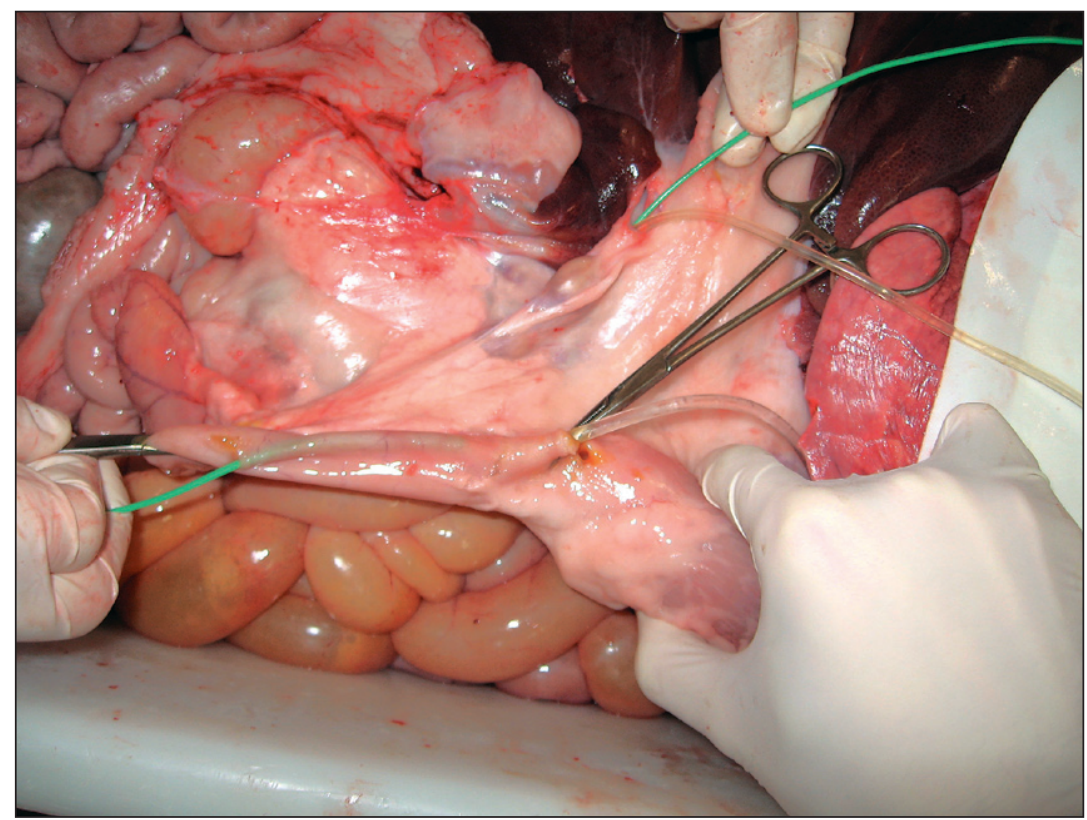

Fig. 1. Radiofrequency ablation of porcine pancreas with perfusion of the duodenum and portal vein with $14^{\circ} \mathrm{C}$ cold saline.

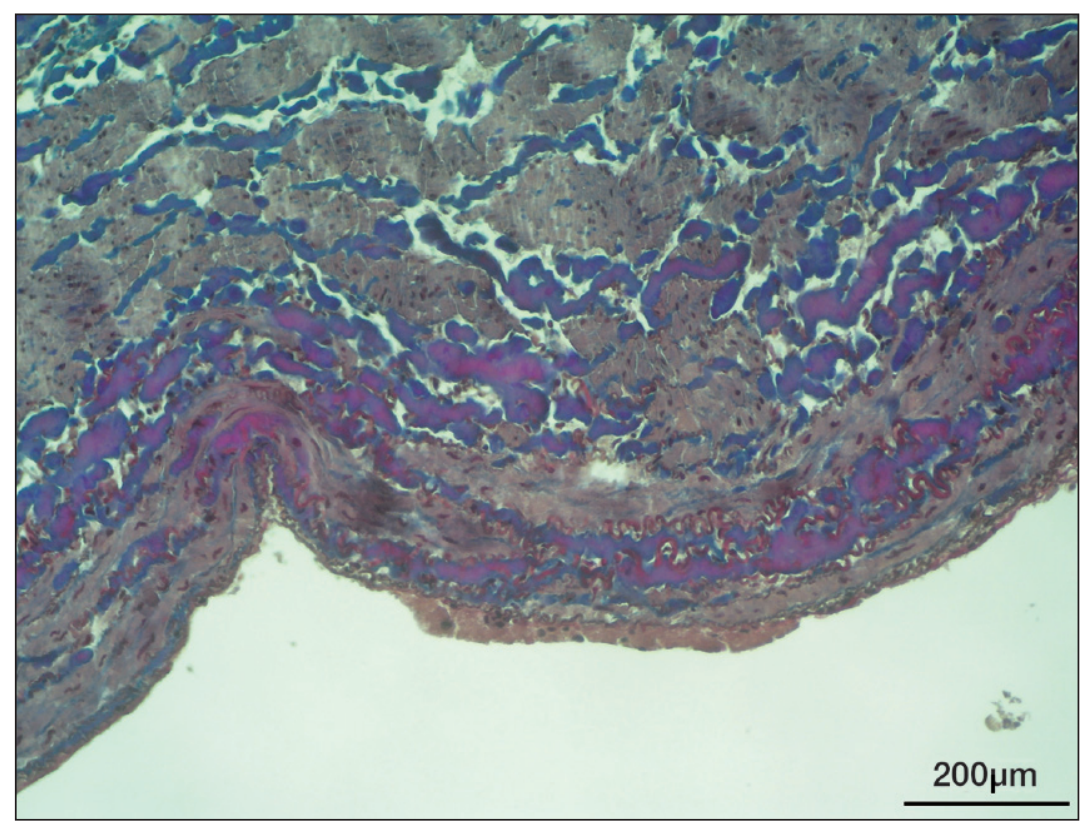

Fig. 2. Portal vein wall (AFOG - acid fuchsin orange G) stain - severe thermal changes visible in the whole width of the portal vein wall. 